\title{
Assessment of kinetic model for ceria oxidation for chemical-looping $\mathrm{CO}_{2}$ dissociation
}

\author{
AE Farooqui*¥o, A Manfredi Pica*, P Marocco*, D Ferrero*, A Lanzini*, S Fiorilli**, J Llorca ${ }^{¥}$, \\ M Santarelli* \\ * Energy Department (DENERG), Politecnico di Torino, Corso Duca degli Abruzzi 24, Torino \\ 10129, Italy \\ ** Department of Applied Science and Technology (DISAT), Politecnico di Torino, Corso Duca \\ degli Abruzzi 24, Torino 10129, Italy \\ $¥$ Institute of Energy Technologies, Department of Chemical Engineering and Barcelona \\ Research Center in Multiscale Science and Engineering, Universitat Politècnica de Catalunya, \\ EEBE, Eduard Maristany 10-14, Barcelona 08019, Spain \\ ${ }^{\circ}$ Corresponding author.
}

\section{Abstract}

Chemical looping technologies are identified as to have a great potential for $\mathrm{CO}_{2}$ capture and fuels synthesis. Oxygen carriers are the fundamental component of a chemical looping process, and the choice of stable and efficient carriers with fast redox kinetics is the key for the successful design of the process. Hence, understanding the reaction kinetics is of paramount importance for the selection of an appropriate oxygen carrier material. This work provides a method for kinetic model selection based on statistical approach to identify the reaction mechanism. The study experimentally investigates the oxidation kinetics of $\mathrm{CeO}_{2-\delta}$ by $\mathrm{CO}_{2}$ and applies a statistical method for the selection of the best-fitting kinetic model for the reaction. The kinetic study is performed in the temperature range of $700-1000^{\circ} \mathrm{C}$ with $\mathrm{CO}_{2}$ concentration between $20-40 \%$ in the feed. The measured peak rates of $\mathrm{CO}$ production on ceria were influenced both by temperature and concentration of reactant, showing a marked increase with the temperature and $\mathrm{CO}_{2}$ fraction, from $13.25 \mathrm{ml} / \mathrm{min} / \mathrm{g}$ at $700^{\circ} \mathrm{C}$ and $20 \% \mathrm{CO}_{2}$ in feed to $46.08 \mathrm{ml} / \mathrm{min} / \mathrm{g}$ for $40 \%$ $\mathrm{CO}_{2}$ and $1000^{\circ} \mathrm{C}$. The total $\mathrm{CO}$ production showed more influence of temperature than $\mathrm{CO}_{2}$ 
concentration, with a maximum $\mathrm{CO}$ yield of $33.66 \mathrm{ml} / \mathrm{g}$ at $1000^{\circ} \mathrm{C}$ and $40 \% \mathrm{CO}_{2}$. The identification of the oxidation kinetic model is performed by fitting different reactions models to the measured reaction rates and statistically comparing them using Residual sum of squares (RSS), Akaike information criterion (AICc) and the F-test for the selection of the best-fitting one. Models corresponding to the nucleation and grain growth reaction mechanism provided a good fit of the data, with the Sestak-Berggren (SB) model showing the best approximation of the measured rate of reaction with evaluated activation energy of $78.5 \mathrm{~kJ} / \mathrm{mol}$ for the $\mathrm{CO}_{2}$ oxidation.

\section{Introduction}

Global warming constitutes currently one of the most discussed environmental issues, and the scientific community converges toward the awareness that the human impact on the environment is becoming more and more unsustainable. Most recognized responsible of such phenomenon are the greenhouse gases, mainly the carbon dioxide. One of the approaches to reduce $\mathrm{CO}_{2}$ emissions from fossil fuels is carbon capture and sequestration (CCS). Carbon dioxide can be separated from the emissions originated from fossil fuels combustion by using different technologies (e.g., absorption, adsorption, cryogenic distillation, etc.) and then sequestrated in geological formations or injected into nearly depleted oil/gas reservoirs for Enhanced Oil Recovery (EOR). Although several CCS technologies exist, there are significant challenges still associated with CCS, mostly due to safety and long term stability and economic reasons $\left[^{1}\right]$. The energy needs and environmental concerns, thus, drive to look after alternative approaches, such as $\mathrm{CO}_{2}$ splitting and/or utilization for the synthesis of fuels (e.g., methanol) ${ }^{2-}$ $\left.{ }^{4}\right]$.

Thermochemical dissociation of $\mathrm{CO}_{2}$ (also called as chemical looping $\mathrm{CO}_{2}$ splitting) into $\mathrm{CO}$ attracted significant interest after the initial success of thermochemical $\mathrm{H}_{2} \mathrm{O}$ splitting $\left.{ }^{5}\right]$. In fact, 
thermochemical cycles were initially focused on hydrogen production from water splitting using oxygen carrier materials. In a thermochemical cycle, the oxygen carrier participates in two separate redox reactions, in which it is first thermally reduced and subsequently oxidized by $\mathrm{H}_{2} \mathrm{O}$ or $\mathrm{CO}_{2}$. The thermal reduction (TR) step of the cycle is endothermic and requires a higher valence metal oxide, which releasing oxygen upon supply of external heat forms a lower valence oxide of the metal. In the second step, the reduced metal oxide is oxidized back to higher valence state by taking oxygen from $\mathrm{H}_{2} \mathrm{O}$ or $\mathrm{CO}_{2}$ to form $\mathrm{H}_{2}$ or $\mathrm{CO}\left[{ }^{6}\right]$. Here, a reduction temperature higher than the oxidation one is the thermodynamic constraint for this process to be attainable, as shown in Figure 1.

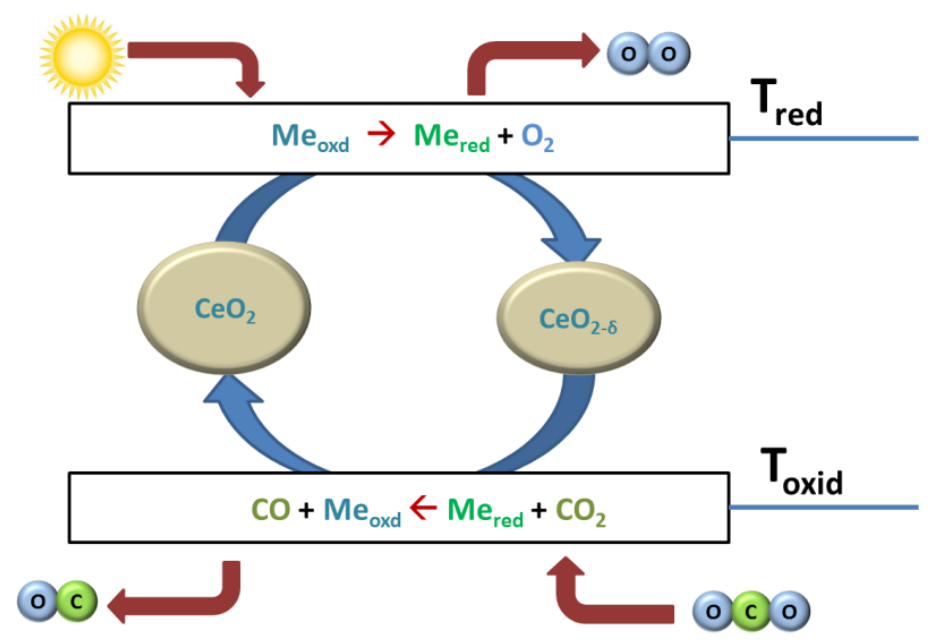

Figure 1 Schematic of chemical looping $\mathrm{CO} 2$ splitting to produce syngas with metal oxide looping between two-step redox cycle

The net outcome of the cycle is the same as splitting $\mathrm{H}_{2} \mathrm{O}-$ or $\mathrm{CO}_{2}-$ into $\mathrm{H}_{2}$ and $\mathrm{O}_{2}-$ or $\mathrm{CO}$ and $\mathrm{O}_{2}$ - in a single step reaction, but compared to a single-step thermolysis reaction, it requires a sensibly lower temperature (e.g., water thermolysis takes place at above $2300{ }^{\circ} \mathrm{C}$ ) and it also bypasses the problem of formation of explosive mixtures by producing separate streams of $\mathrm{H}_{2}$ or $\mathrm{CO}$ and $\mathrm{O}_{2}\left[{ }^{7,8}\right]$. 
In this work, ceria-based thermochemical looping for $\mathrm{CO}_{2}$ splitting is investigated. Ceria has been chosen as it is considered one of the most promising redox oxygen carriers because of its fast chemistry, high ionic diffusivity and large oxygen storage capacity. Using oxygen-deficient ceria, $\mathrm{CO}_{2}$ is dissociated into $\mathrm{CO}$ via:

Oxidation: $\mathrm{CeO}_{2-\delta}+\delta \mathrm{CO}_{2}(\mathrm{~g}) \rightarrow \mathrm{CeO}_{2}+\delta \mathrm{CO}(\mathrm{g})$

Thermal reduction: $\mathrm{CeO}_{2} \rightarrow \mathrm{CeO}_{2-\delta}+0.5 \delta \mathrm{O}_{2}(\mathrm{~g})$

where $\delta$ is the non-stoichiometric oxygen capacity, corresponding to the surface oxygen vacancies determining the extent of $\mathrm{CO}_{2}$ dissociation (Eq. 1). Vacancies are formed back in the reduction step by the release of oxygen (Eq. 2). In thermochemical $\mathrm{CO}_{2}$ splitting the oxygen removal step can be achieved either by heating ceria to a high temperature $\left(\sim 1400^{\circ} \mathrm{C}\right)$ using concentrated solar irradiation (Eq. 2) or by reducing the oxygen carrier using $\mathrm{H}_{2}$ (or even other fuels, e.g. $\mathrm{CH}_{4}$ ), also called as reactive-chemical looping $\mathrm{CO}_{2}$ splitting (RCLCS).

Hydrogen reduction: $\mathrm{CeO}_{2}+\delta \mathrm{H}_{2}(\mathrm{~g}) \rightarrow \mathrm{CeO}_{2-\delta}+\delta \mathrm{H}_{2} \mathrm{O}(\mathrm{g})$

The transfer of oxygen between the two redox steps exploits the oxygen non-stoichiometric capacity of the ceria, and the oxygen carrier remains intact at the end of the cycle. Though the redox cyclic process to produce syngas shows a promising potential, there are major challenges to achieve the high temperature required for the thermal reduction, which needs a concentrated solar plant (CSP) [ $\left.{ }^{9}\right]$. Apart from high heat demand, the large temperature swing between the two-steps render the process to be less efficient if not designed in a proper way.

Among many oxygen carrier materials for $\mathrm{CO}_{2}$ splitting, ceria has been widely investigated in experimental studies. A number of experiments $\left[{ }^{10-18}\right]$ have demonstrated the feasibility of $\mathrm{CO}_{2}$ splitting with ceria, as listed in Table 1. However, only few studies reported the reaction kinetics, mainly following equilibrium approach, defect model theory, empirical solid state kinetics 
models $\left[{ }^{19-27}\right]$. Arifin $\left[{ }^{27}\right]$ has investigated the kinetics of splitting of water and $\mathrm{CO}_{2}$ over ceria and found that it is difficult to converge on a single kinetic model that adequately predicts the $\mathrm{CO}$ production behavior from thermally reduced ceria over the entire temperature range investigated. In order to achieve a high quality fit to the data, three separate had to be used within the F family of models to give the best-fit to the $\mathrm{CO}$ transient signal with different kinetic parameters. Bulfin et al $\left[{ }^{26}\right]$ developed an analytical kinetic model to fit experimental data and found that R3 model gives the best fit results below $800^{\circ} \mathrm{C}$. Ackerman et al $\left[{ }^{28}\right]$ reported that $\mathrm{D} 2$ model provides the best-fitting for ceria oxidation at $1400^{\circ} \mathrm{C}$. The lack of agreement between the kinetic models based on various experimental studies is a point of observation. The difference of the reaction mechanisms adopted could be a consequence of variations in the experimental conditions or the morphology of $\mathrm{CeO}_{2}$ samples. Therefore, the present work aims to statistically analyze the solidstate reaction kinetics models that describe the oxidation of non-stoichiometric ceria with $\mathrm{CO}_{2}$ by comparing their fitting goodness to a wide set of experimental measures. These reaction kinetic models are listed in Table S1 (supplementary data) with detailed formula.

In this work, $\mathrm{CO}_{2}$ dissociation over ceria is investigated by experiments and the measured reaction rates are used for kinetic models selection based on statistical approach to identify the reaction mechanism.

Isothermal redox cycles of $\mathrm{CeO}_{2}$ commercial powders are carried out in a horizontal tubular reactor in the temperature range of $700-1000^{\circ} \mathrm{C} . \mathrm{H}_{2}$ is used for the ceria reduction in order to explore the maximum non-stoichiometric capacity $(\delta)$ achieved at a certain temperature while using different concentration of carbon dioxide in the oxidation step. The temperature swing is thus replaced by isothermal operation for developing the kinetics. The $\mathrm{CO}$ production during the oxidation reaction is measured using an online mass spectrometer. Based on the reactivity data 
from the experiments, many kinetic models based on different reaction mechanisms (i.e., reaction order, geometrical contracting, diffusion, and nucleation models) are compared using statistical criteria - Residual sum of squares (RSS), Akaike information criterion (AICc) and the F-test - and the best-fitting model is selected and the corresponding ceria oxidation mechanism is identified.

Table 1.Total $\mathrm{CO}$ production by $\mathrm{CO}_{2}$ splitting on $\mathrm{CeO}_{2}$ for thermally reduced and $\mathrm{H}_{2}$ reduced Ceria for various redox temperatures cited in the literature

\begin{tabular}{lllll}
\hline $\begin{array}{l}\text { Temp } \\
(\text { Red/Ox) }\end{array}$ & Total CO $(\mathbf{m l} / \mathbf{g})$ & $\begin{array}{l}\text { Feed CO } \\
(\boldsymbol{\%})\end{array}$ & Reducer & Ref \\
\hline $1500 / 800$ & 6.28 & $50 \%$ & thermal & {$\left[{ }^{7}\right]$} \\
$1400 / 1000$ & 2.35 & $50 \%$ & thermal & {$\left[{ }^{10}\right]$} \\
$1400 / 1000$ & 2.24 & $50 \%$ & thermal & {$\left[{ }^{11}\right]$} \\
$1600 / 1000$ & 4.91 & $60 \%$ & thermal & {$\left[{ }^{9}\right]$} \\
$1527 / 827$ & 1.99 & $8.3 \%$ & thermal & {$\left[{ }^{6}\right]$} \\
$1200 / 850$ & 0.83 & $25 \%$ & thermal & {$\left[{ }^{12}\right]$} \\
$1500 / 800$ & 4.03 & $38.5 \%$ & thermal & {$\left[{ }^{13}\right]$} \\
$1500 / 1500$ & 2.02 & $100 \%$ & thermal & {$\left[{ }^{13}\right]$} \\
$1400 / 1000$ & 1.23 & $100 \%$ & thermal & {$\left[{ }^{15}\right]$} \\
$1100 / 500$ & 13.45 & $0.5-40 \%$ & $\mathrm{H}_{2}$ & {$\left[{ }^{16}\right]$} \\
$827 / 827$ & 20.93 & $4 \%$ & $\mathrm{H}_{2}$ & {$\left[{ }^{18}\right]$} \\
$900 / 900$ & 22.71 & $14.30 \%$ & $\mathrm{H}_{2}$ & {$\left[{ }^{17}\right]$} \\
$700 / 700$ & 4.17 & $14.30 \%$ & $\mathrm{H}_{2}$ & {$\left[{ }^{17}\right]$} \\
$700 / 700$ & $7.57-9.19$ & $20-40 \%$ & $5 \% \mathrm{H}_{2} / \mathrm{Ar}$ & Present study \\
$800 / 800$ & $17.73-19.28$ & $20-40 \%$ & $5 \% \mathrm{H}_{2} / \mathrm{Ar}$ & Present study \\
$900 / 900$ & $23.90-28.05$ & $20-40 \%$ & $5 \% \mathrm{H}_{2} / \mathrm{Ar}$ & Present study \\
$1000 / 1000$ & $28.51-33.68$ & $20-40 \%$ & $5 \% \mathrm{H}_{2} / \mathrm{Ar}$ & Present study \\
\hline
\end{tabular}

\section{Experimental section}

\subsection{Reaction activity testing}

The experimental setup consists of a horizontal alumina tubular reactor, a control unit, a gas delivery system and a real-time gas analysis system with an online mass spectrometer. The system layout and the details of the reactor are shown in Figure 2. Three Bronkhorst EL-FLOW 
mass flow controllers (MFCs) are used for the gas flow control. The reactor is made of an alumina tube positioned inside a tubular furnace (Lenton UK) that provides an isothermal environment up to $1600^{\circ} \mathrm{C}$. As shown in Figure 2, the reactor consists of an outer alumina tube with $90 \mathrm{~cm}$ length, inner diameter (i.d) of $50 \mathrm{~mm}$, an inner concentric $12 \mathrm{~mm}$ o.d alumina tube and $10 \mathrm{~mm}$ i.d with $1 \mathrm{~m}$ length. The gas flow passes through the inner tube where the sample is placed in the center supported with quartz wool. A quadrupole mass spectrometer (QMS) (Hiden Analytical Inc.) is used to analyze the gas composition. The QMS has a response time of less than $0.3 \mathrm{~s}$ and a wide bandwidth of species detection capability.

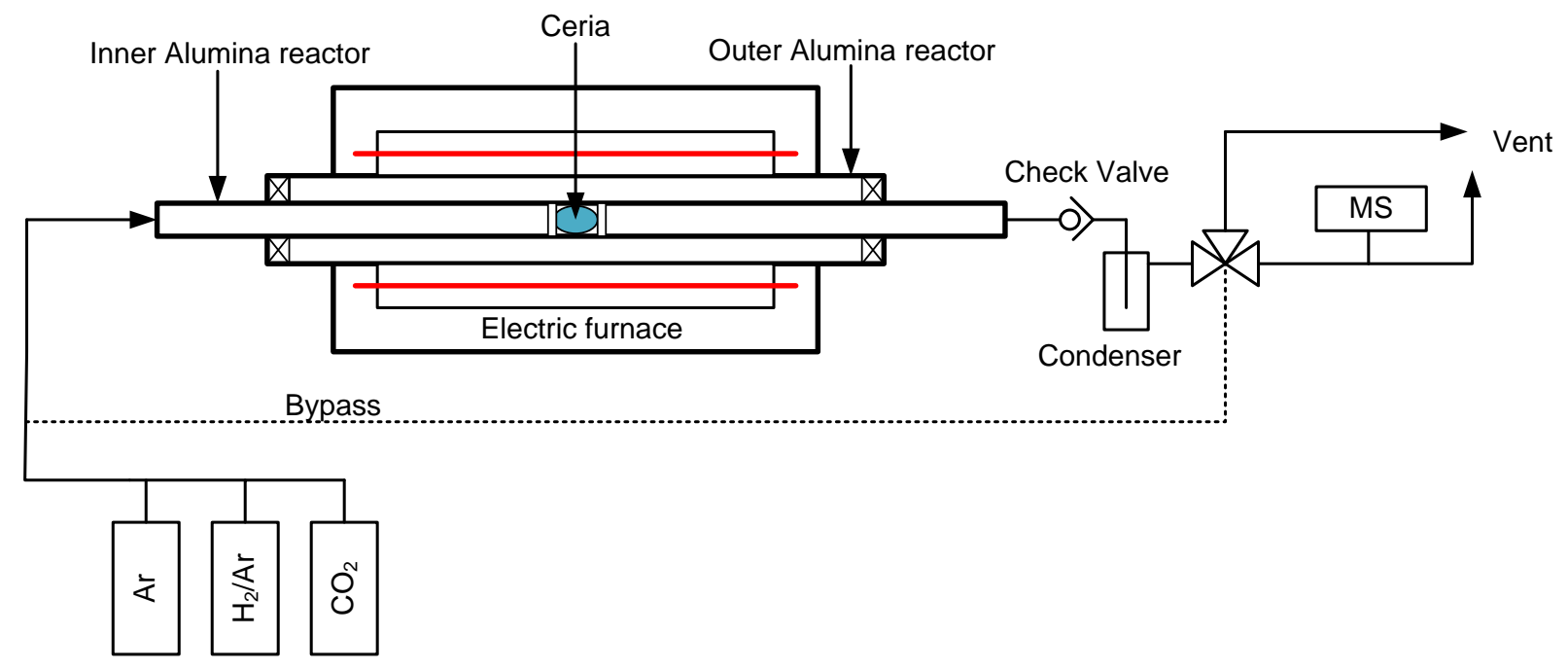

Figure 2. Experimental set up

Commercial ceria powder from Alfa Aesar (99.95\% purity) is used for the reaction study. The test sample was crushed and sieved to 32 micron. A $250 \mathrm{mg}$ amount of ceria powder is embedded in quartz wool and placed at the center of the inner alumina tube. The total flow rate into the reactor during the oxidation step is maintained constant at $120 \mathrm{Nml} / \mathrm{min}$ (GHSV 28800 $\mathrm{mL} / \mathrm{g} / \mathrm{h}$ ) and the $\mathrm{CO}_{2}$ mole fraction is varied between $20 \%-40 \%$, balance argon. A mixture of Hydrogen and Argon (5\% $\mathrm{H}_{2}$ concentration) is used as a fuel for the reduction step, as the focus of the present study is only the oxidation step and the analysis of its kinetic (Eq. 4). As the 


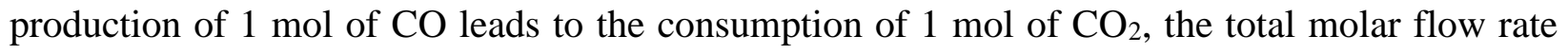
throughout the control volume remains constant.

Each experiment is based on a cycle of four steps. The first is the ceria reduction step where the mixture of Argon and Hydrogen is sent for 30 min to ensure complete reduction. Then, a purging stream of pure Argon is sent for 10 minutes, in order to remove the $\mathrm{H}_{2}$ present in the fixed bed. The next step is oxidation reaction where a mixture of Argon and $\mathrm{CO}_{2}$ with different concentrations $(20 \%, 30 \%$ and $40 \%)$ of the latter is sent for $15 \mathrm{~min}$. Final step is again the purging with pure Argon for 10 minutes. Isothermal redox cycles were performed at 700, 800, 900 and $1000^{\circ} \mathrm{C}$. The measure of $\mathrm{CO}$ concentration in the outlet flow of the reactor allowed to extrapolate the reaction rate of the oxidation reaction:

$\dot{\omega}_{\mathrm{CO}}=\frac{X_{\mathrm{CO}, \text { out }} \dot{n}_{\text {ox,out }}}{m_{\mathrm{CeO}_{2}}}=\frac{X_{\mathrm{CO}, \text { out }}}{m_{\mathrm{CeO}_{2}}} \frac{P^{0} \dot{V}_{o x, \text { in }}^{0}}{R T^{0}} \quad(\mathrm{Eq} 4)$

where $X_{C O, \text { out }}$ is the measured mole fraction of $\mathrm{CO}$ at the exit of the reactor, $\dot{n}_{o x, \text { out }}$ is the total molar outflow rate of the gas mixture for the oxidation, which is equal to the inlet molar flow, while $P^{0}, T^{0}$ and $\dot{V}_{o x, i n}^{0}$ are the pressure, temperature and the total volumetric inflow rate at standard temperature and pressure (STP). The reaction rates are normalized by the total ceria sample $m_{\mathrm{CeO}_{2}}$ - i.e. $250 \mathrm{mg}$ - used in the measurement. The derivation assumes the quasi-steadystate and neglects the accumulation or depletion effect in the control volume as the residence time of the gases is negligible with respect to the characteristic time of the redox conversion.

The bulk-phase non-stoichiometry change of ceria has been evaluated from the extrapolated oxidation rate. The oxidation reaction can be rewritten as the following equation (Eq. 5):

$\mathrm{CO}_{2}(\mathrm{~g})+\frac{1}{\delta} \mathrm{CeO}_{2-\delta_{1}} \rightarrow \mathrm{CO}(\mathrm{g})+\frac{1}{\delta} \mathrm{CeO}_{2-\delta_{2}}$ 
where $\delta_{1}$ is the non-stoichiometry reached after reduction step, $\delta_{2}$ is non-stoichiometry reached after the oxidation of ceria step, and $\delta=\delta_{1}-\delta_{2}$ is the bulk-phase non-stoichiometry change, which is calculated according to the following equation:

$\delta(\mathrm{t})=\frac{\mathrm{n}_{\mathrm{O}}(\mathrm{t})}{\mathrm{n}_{\mathrm{CeO}_{2}}} \quad(\mathrm{Eq} 6)$

where $\mathrm{n}_{\mathrm{O}}(\mathrm{t})=\int_{0}^{t} \dot{\omega}_{\mathrm{CO}} d t$ is the accumulated intake of oxygen ions, $\mathrm{n}_{\mathrm{CeO}_{2}}=\mathrm{m}_{\mathrm{CeO}_{2}} / \mathrm{M}_{\mathrm{CeO}_{2}}$ is the moles of ceria used in the experiment, with $\mathrm{M}_{\mathrm{CeO}_{2}}$ its molecular weight.

The non-stoichiometry is basically the amount of oxygen that the solid reactant can accept from the $\mathrm{CO}_{2}$, so, starting from a reduced state, it decreases while the reaction occurs because the ceria is oxidized. At the end of the oxidation, oxygen vacancies are depleted and no more oxygen is incorporated in the material. The maximum non-stoichiometry is affected by the temperature, with an increase of available vacancies when the ceria is reduced at higher temperature.

\subsection{Material characterization}

To confirm the lattice structure of the samples before and after cycles, X-ray diffraction (XRD) was performed using a PANalytical X'pert MPD Pro diffractometer with Ni-filtered $\mathrm{Cu}$ $\mathrm{K} \alpha$ irradiation (wavelength $1.5406 \AA$ ). All samples were scanned in the $2 \theta$ range from $5^{\circ}$ to $80^{\circ}$ with a step size of $0.2 \%$. For a rough estimation on sintering effect, crystallite size of samples before and after test were calculated from the Scherer equation (Equation 7) based on the strongest peak.

$$
D=\frac{0.9 \lambda}{\beta \cos \theta}
$$


where $\mathrm{D}, \lambda, \beta$, and $\theta$ are the grain size, $\mathrm{X}$-ray wavelength, line broadening at half the maximum intensity, and Bragg angle respectively. Crystallite micrographs were obtained with a field emission scanning electron microscope (SEM, JSM7800F) at an accelerating voltage of $3 \mathrm{kV}$.

\section{Reactivity results}

The results of the tests have been firstly investigated considering the $\mathrm{CO}_{2}$ splitting performance of the tested materials in terms of $\mathrm{CO}$ production rate $(\mathrm{Nml} / \mathrm{min} / \mathrm{g})$ and total $\mathrm{CO}$ yield $(\mathrm{Nml} / \mathrm{g})$. The different conditions in which the tests were carried out allowed a comparison with the purpose to understand the dependence of the performance of the oxygen carrier on temperature and reactant gas concentration.

\subsection{Effect of temperature}

Figure 3 shows the $\mathrm{CO}$ production rate as a function of temperature from 700 to $1000^{\circ} \mathrm{C}$. In each plot, the reaction rate exhibits a fast initial stage, followed by a decrease. During oxidation, the fast initial $\mathrm{CO}$ increase corresponds to the rapid oxygen vacancies ion incorporation. Both temperature and reactant concentration play a role in determining the maximum rate. The peak rate varies nonlinearly with temperature and for temperature lower than $700^{\circ} \mathrm{C}, \mathrm{CO}$ production is limited due to the low oxygen non-stoichiometric factor. The increase of temperature to $800^{\circ} \mathrm{C}$ showed significant enhancement of peak production rates, nearly 1.5 times. Further increase of temperature from $800^{\circ} \mathrm{C}$ to $1000^{\circ} \mathrm{C}$ produces a less marked peak growth. All the peaks occur at around 15-30 seconds, and the peak duration increases with the temperature, due to the higher amount of available oxygen sites. After the peak, $\mathrm{CO}$ production rates decreases sharply at all the temperatures and approaches zero between 90 and 110 seconds. This shows strong temperature dependence of the $\mathrm{CO}$ rate profile, which becomes taller and wider at higher temperature, indicating a high activation barrier associated with the $\mathrm{CO}_{2}$ splitting process $\left[{ }^{19}\right]$. 

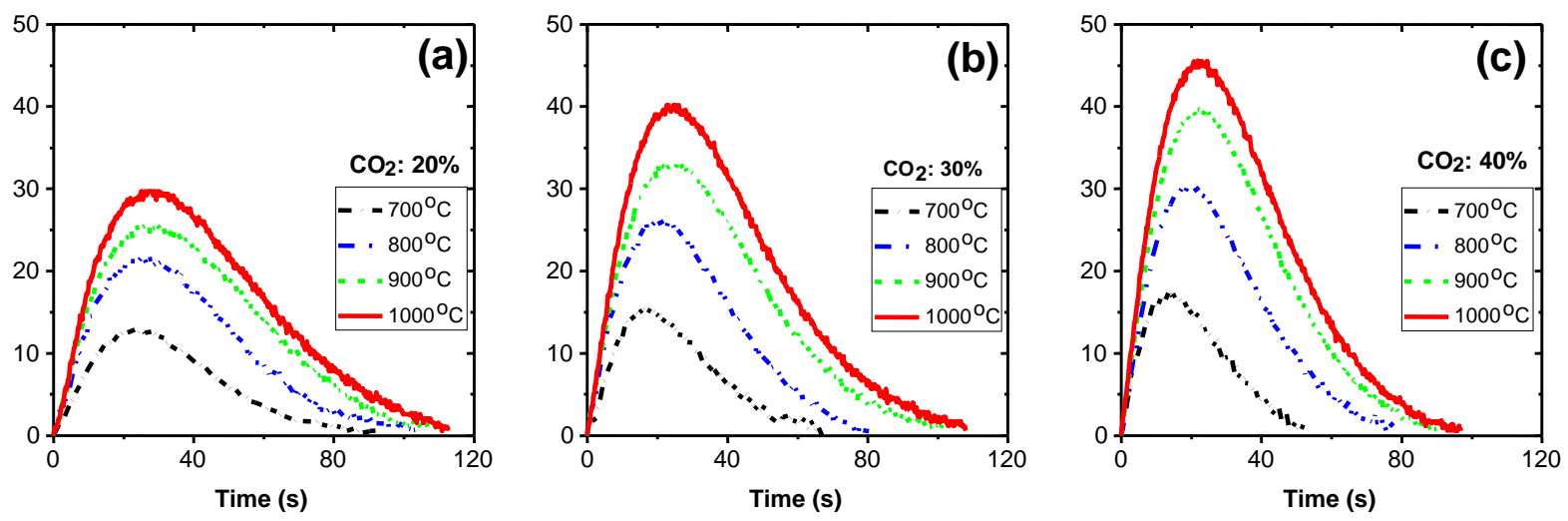

Figure 3. CO proguci: $\mathrm{CO}_{2}$ in the feed, (b) $30 \%$ mole fraction of $\mathrm{CO}_{2}$ in the feed, (c) $40 \%$ mole fraction of $\mathrm{CO}_{2}$ in the feed with Argon. Temperature is varied from $700-1000^{\circ} \mathrm{C}$.

Figure 4(a) emphasizes the observed behavior of the peak rates at varying temperature for different $\mathrm{CO}_{2}$ molar fractions. The peak rates exhibit a profile with a rapid increase around a temperature of $800^{\circ} \mathrm{C}$. Total $\mathrm{CO}$ production during the oxidation step in the redox cycle is illustrated in Figure 4(b). In all the cases, an almost linear rise of total CO production is observed from $9 \mathrm{ml} / \mathrm{g}$ at $700^{\circ} \mathrm{C}$ to $33 \mathrm{ml} / \mathrm{g}$ at $1000^{\circ} \mathrm{C}$. Figure 4 also shows that the effect of $\mathrm{CO}_{2}$ concentration on the total production of $\mathrm{CO}$ is sensibly lower than temperature variation. The strong temperature dependence is evident from the earlier studies [ $\left.{ }^{14,16,25,29}\right]$.
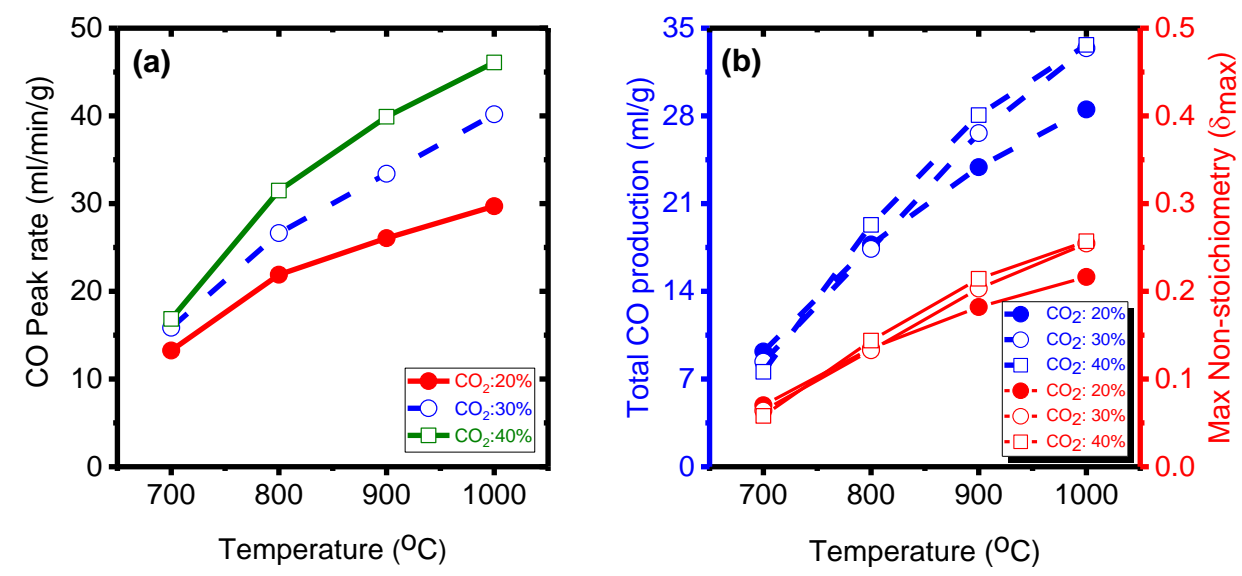
Figure 4. (a) Peak $\mathrm{CO}$ rates as a function of temperature and $\mathrm{CO}_{2}$ mol fraction during oxidation and (b) total $\mathrm{CO}$ production and maximum non-stoichiometry $\delta$ max attained as a function of temperature and $\mathrm{CO}_{2}$ mol fraction during oxidation.

Figure 4(b) also shows the maximum non-stoichiometric factor $\left(\delta_{\max }\right)$ of ceria reached during oxidation step for varying temperature for different $\mathrm{CO}_{2}$ concentration in feed. The concentration of oxygen vacancies in the ceria increases only very slightly with an increase of $\mathrm{CO}_{2}$ concentration in the feed, mainly at the higher temperatures.

Figure 5 compares the difference in profiles of the non-stoichiometry $(\delta)$ as calculated in equation 6 during oxidation. The initial stage of oxidation ends within 20 seconds, but accounts for more than $70 \%$ of the overall $\delta$ change, while the remaining oxidation leads to a minor change of non-stoichiometry. It is evident that the oxygen carrying capacity increases due to higher extent of non-stoichiometry achieved at higher temperatures. It can be noted that the nonstoichiometry increases from 0.07 to 0.21 in the $700-1000^{\circ} \mathrm{C}$ temperature range for $20 \% \mathrm{CO}_{2}$ mole fraction, and a maximum of 0.25 is reached at $1000^{\circ} \mathrm{C}$ for $30 \% \mathrm{CO}_{2}$ mole fraction. Similar non-stoichiometry results for oxidation are reported elsewhere $\left[{ }^{16}\right]$.
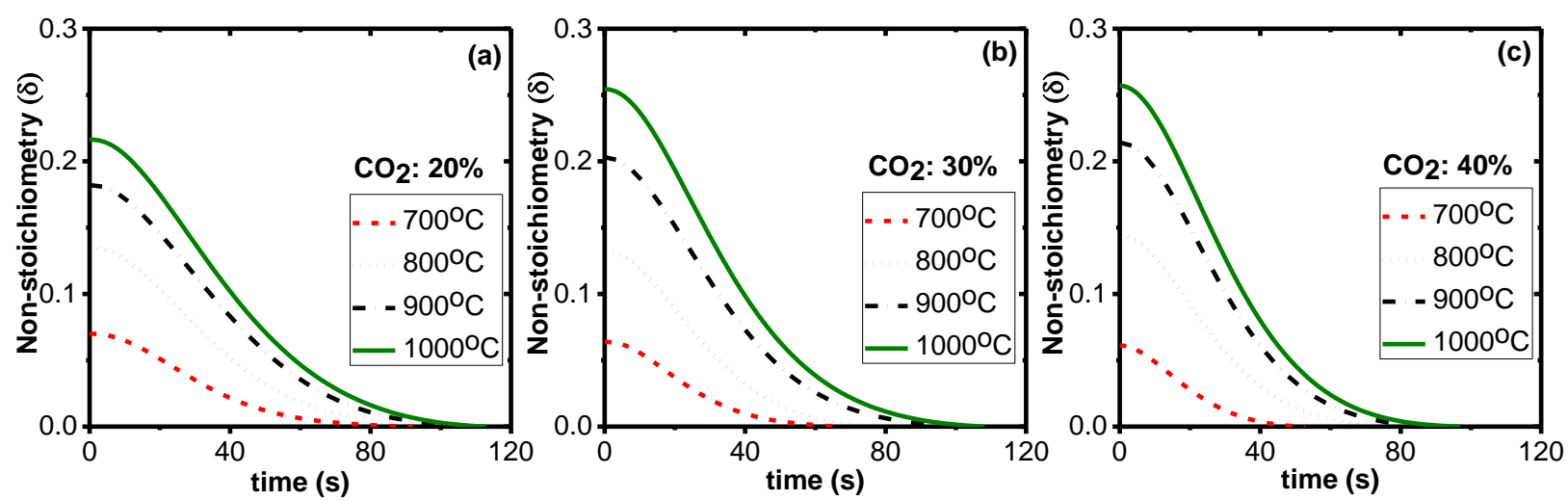

Figure 5. Non stoichiometry during oxidation step with varying temperature from $700-1000^{\circ} \mathrm{C}$ for (a) $20 \%$ mole fraction of $\mathrm{CO}_{2}$ (b) $30 \%$ mole fraction of $\mathrm{CO}_{2}$ and (c) $40 \%$ mole fraction of $\mathrm{CO}_{2}$. 


\subsection{Effect of $\mathrm{CO}_{2}$ concentration}

The effect of concentration of the oxidant is investigated to identify the dependence of it on kinetics and the influence on conversion time.

Figure 3 shows that the reaction time reduces with the increase of $\mathrm{CO}_{2}$ partial pressure in the feed. Higher peak rates and reduced time to achieve peak are achieved with higher $\mathrm{CO}_{2}$ concentration. Similar profiles were reported by Z Zhou et al $\left[{ }^{17}\right]$. Even if the conversion time reduces with the increase of $\mathrm{CO}_{2}$ mole fraction in the feed, the growth of $\mathrm{CO}$ peak rate with $\mathrm{CO}_{2}$ concentration balances this effect and the total conversion remains same for that particular point of interest, as shown in Figure 4(b). For instance, the $\delta_{\max }$ for temperature $700^{\circ} \mathrm{C}$ is 0.06 for all the $\mathrm{CO}_{2}$ concentration range, and only at higher temperature it varies slightly with $\mathrm{CO}_{2}$ fraction. It articulates the maximum delta is increased linearly with temperature but with it has little effect of $\mathrm{CO}_{2}$ concentration in the feed.

Figure 6(a) shows the effect of concentration within 20-40\% concentration (balance Argon) at $900^{\circ} \mathrm{C}$. It is observed that there is a shift of peak rate position from $30 \mathrm{sec}$ to $15 \mathrm{sec}$ with an increase of $\mathrm{CO}_{2}$ concentration. For higher temperatures this behavior is not seen and most the peak rate position were $20 \mathrm{sec}$ to $30 \mathrm{sec}$ from the start of the reaction. Figure 6(b) reports the CO peak rate for the three $\mathrm{CO}_{2}$ concentration investigated for temperature of $900^{\circ} \mathrm{C}$ and it reflects that the $\mathrm{CO}$ peak rate increases linearly with $\mathrm{CO}_{2}$ concentration in feed. The slope of the curve is higher for higher temperature showing more influence for temperatures above $800^{\circ} \mathrm{C}$ (see supplementary data). It can be seen that the total $\mathrm{CO}$ production with different $\mathrm{CO}_{2}$ concentration for a particular temperature is minimal. Similar behavior has been observed for all temperatures. It is seen that for $\mathrm{CO}_{2}$ concentrations of $30 \%$ and $40 \%$ the maximum non-stochiometry ( $\delta$ max) 
reaches the same value as seen in Figure 4(b) and Figure 5(b) and (c). The relatively less dependence of $\mathrm{CO}_{2}$ concentrations have been reported elsewhere $\left[{ }^{7,12,16,19,26,30}\right]$
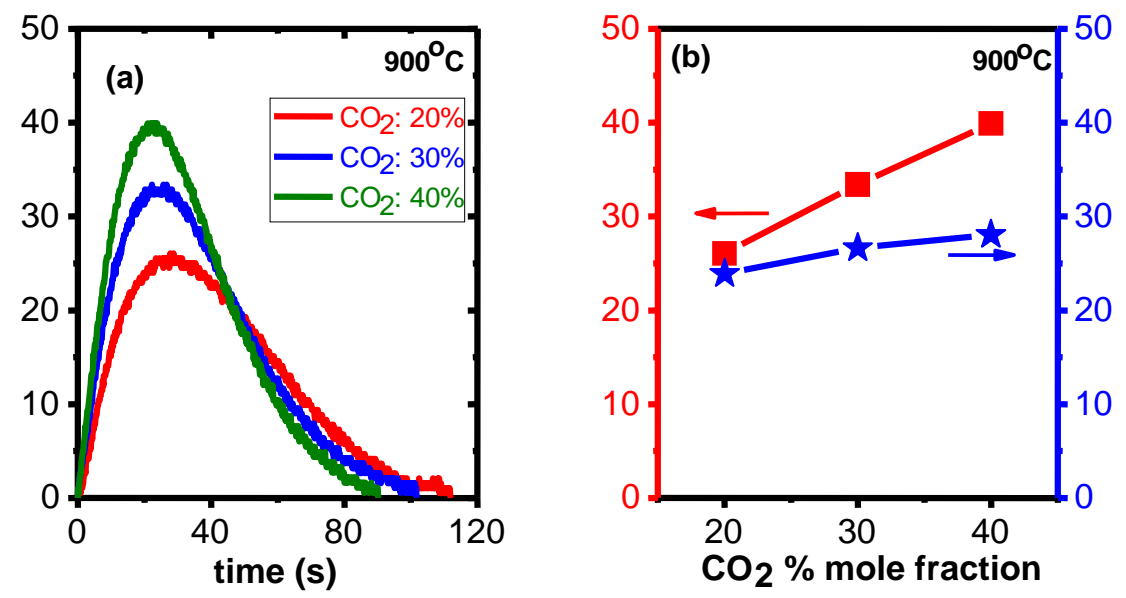

Figure 6(a) $\mathrm{CO}$ production rate versus time for varying concentration of $\mathrm{CO}_{2}$ in the feed for

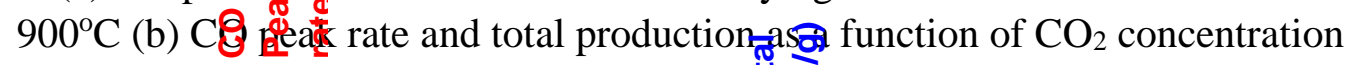

$$
\text { 함 है }
$$

\subsection{Microstructural analysis}

XRD patterns of ceria before and after cycled sample are shown in Figure 7. Cubic fluorite structure was confirmed in both cases. There is slight contamination of silica observed in the after cycled sample; this was due to the quartz wool used to fix the bed in the reactor. Compared to XRD patterns before cycling, the peaks grow stronger after cycling, which indicates a growth of crystalline grains during the high temperature process. Crystallite size of different samples before and after cycles were calculated from Scherrer equation based on the strongest peak (111) and were 11.3 and 12.1 micron respectively. SEM images recorded at high magnification show a coexistence of large ceria particles decorated with much smaller ceria particles. The coexistence of these two ceria particles with different size is also seen in the XRD profiles (narrow, main contribution coming from the large particles and wide contribution in the base of the peaks due to the small particles). The size of the large particles in the before and after cycled samples are 
similar, with a slight sintering in the after cycled sample, in accordance to the XRD patterns; but the small ceria particles sinter strongly after reaction. This is clearly seen in the SEM images and do also coincide with the XRD results (the base of the peaks in the after cycled sample is more narrow than those of the fresh sample).
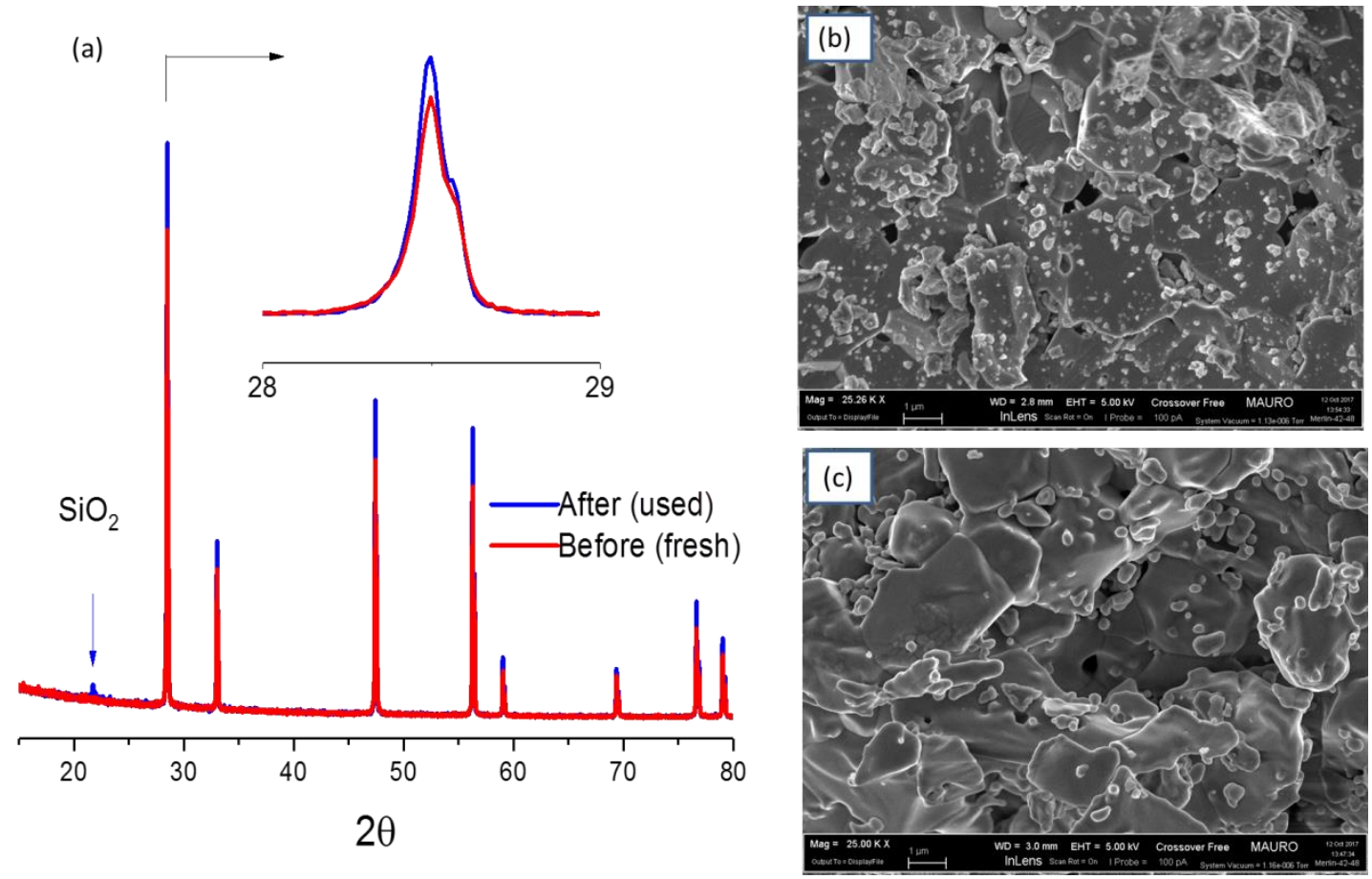

Figure 7. XRD patterns of before and after cycled ceria (b) SEM images of fresh and (c) after cycled ceria.

\section{Kinetic study of ceria oxidation}

Generally, the reaction mechanism of solid state reactions is described using reaction-order models (F), geometrical contraction models (R), diffusion-limited models (D), nucleation models $\left[{ }^{31-34}\right]$ (also called as Avrami-Erofe'ev models, AE), random pore model (RPM) $\left[{ }^{35}\right]$, and the Sestak-Berggren (SB) $\left[{ }^{36}\right]$, and Prout-Tompkins models (PT) $\left[{ }^{37}\right]$. The schematic description of the general kinetic models is illustrated in Figure S3 (supplementary file). 
The evaluation of kinetic model parameters includes isoconversional and isothermal reaction analysis $\left[{ }^{41}\right]$. The working envelope of chemical looping process for narrow temperature range isothermal method was chosen in the present study. As reported in Han et al $\left[{ }^{42}\right]$ the intraparticle heat gradients are negligible and thus the particle can be approximated to be isothermal.

In this paper, the reaction kinetics study is carried out by fitting different models to the experimental data shown in Section 3 in order to identify the solid-state reaction kinetic mechanistic model. The metric usually adopted for the comparison of reaction models with experimental evidences is the reaction rate, measured in term of time profile of reactant conversion or product yield $\left[{ }^{17}\right]$. Three methods are used to compare several solid-state reaction kinetic models against isothermal experimental data. The methods are (a) the fit quality of the transient conversion, ( $\alpha$ vs. t) (b) the fit quality of the transient time derivative of conversion (d $\alpha /$ dt vs. $\alpha$ ). and (c) the Hancock and Sharp Method or model free method $\left[{ }^{43}\right]$. The model free method is used to verify the category of the kinetic model and is presented in supplementary data section.

\subsection{Model fitting method}

The kinetic study needs as input data the extent of reaction during time, which can be derived from the cumulative of the $\mathrm{CO}$ produced as equation 8 .

$$
\operatorname{cum}\left(\dot{\omega}_{\mathrm{CO}, \mathrm{i}}\right)=\sum_{p=1}^{i-1}\left(\dot{\omega}_{\mathrm{CO}, \mathrm{p}}\right)+\dot{\omega}_{\mathrm{CO}, \mathrm{i}}
$$

The extent of reaction $(\alpha)$ for each time instant is given by equation 9 .

$$
\alpha\left(t_{i}\right)=\frac{\operatorname{cum}\left(\dot{\omega}_{\mathrm{CO}, \mathrm{i}}\right)}{\operatorname{cum}\left(\dot{\omega}_{\mathrm{CO}, \mathrm{N}}\right)}
$$


In other words, the extent of reaction at time $t_{i}$ is the ratio between $i$-th value of the cumulative and the final value of the cumulative. It implies that $\alpha$ varies from 0 to 1 . These values are the experimental $\alpha$ s that should be compared with the $\alpha$ s coming from the models.

To obtain the kinetic model, a mathematical equation should be developed. The kinetic expression for gas solid reaction can be expressed as Eq. $10\left[{ }^{39}\right]$ :

$\frac{d \alpha}{d t}=k^{1} \cdot f(\alpha) \cdot[P]^{m} \quad(\operatorname{Eq} 10)$

Where $\alpha$ is the conversion, $k^{1}=A \exp \left(-E_{a} / R T\right)$ and $P$ is the partial pressure of $\mathrm{CO}_{2}, m$ is the reaction order and $\mathrm{f}(\alpha)$ is a function of $\alpha$ depending on the reaction mechanism. The coefficients $A$ and $E_{a}$ are the Arrhenius parameters; $E_{a}$ being the activation energy and $R$ is the gas constant that is equal to $8.314 \mathrm{~J} / \mathrm{mol} / \mathrm{K}$.

The first step of calculations was the fitting of the model with the raw data. For this purpose, Eq. (9) was transformed to Eq. (11):

$\frac{d \alpha}{f(\alpha)}=K \cdot d t(\mathrm{Eq} 11)$

Where $K=k^{1} \cdot P^{m}$ is expressed in terms of partial pressure of $\mathrm{CO}_{2}$. The integral of the reaction model is expressed by integrating equation 11 .

$$
g(\alpha)=\int_{0}^{\alpha} \frac{d \alpha}{f(\alpha)}
$$

In other terms, equation 12 is also expressed as:

$$
g(\alpha)=K \cdot t
$$

The slope of the curve $g(\alpha)$ vs $t$ is the parameter $K$. The slope between natural $\log$ of $K$ vs $1 / \mathrm{T}$ (Eq. 14) gives the activation energy as negative slope. The intercept will be $\ln \left(\mathrm{AP}^{\mathrm{m}}\right)$ where $\mathrm{P}$ is the partial pressure of $\mathrm{CO}_{2}$. The reaction order ' $\mathrm{m}$ ' was evaluated by plotting $\ln \left(\mathrm{AP}^{\mathrm{m}}\right)$ vs. $\ln \mathrm{P}$ 
(see Eq. 15) and the slope would be the reaction order and the intercept would help in yielding the ' $A$ ' value.

$\ln K=-\frac{E_{a}}{R T}+\ln A \cdot P^{m} \quad(\mathrm{Eq} 14)$

$\ln \left[A \cdot P^{m}\right]=\ln A+m \ln P \quad(\mathrm{Eq} 15)$

The basic procedure here is to utilize the kinetic expressions of the models reported in Table S1 to match the experimental data in the form of $\mathrm{d} \alpha / \mathrm{dt}$ vs $\alpha$ and $\alpha$ vs t profiles by fitting the value of the $K$ parameter, and then select the models with smallest residual sum of squares (RSS) among candidate models with the same number of parameters $\left[{ }^{40}\right]$. Two parameters models (i.e., Avrami-Erofe'ev (AEn)) and three parameters models (i.e., Sestak-Berggren (SB)) need also the evaluation of additional parameters.

For Avrami-Erofe'ev (AEn) model its exponent $n$ need to be evaluated. The validation of Avrami exponent $(n)$ starts from the identification of a particular value of conversion, $\alpha_{\mathrm{M}}$, which is evaluated at the maximum $\mathrm{d} \alpha / \mathrm{dt}$ for each experiment. Then the parameter ' $\mathrm{n}$ ' comes from the Eq 16.

Avrami exponent $\mathrm{n}=\frac{1}{1+\ln \left(1-\alpha_{M}\right)} \quad($ Eq 16)

For SB model, we need to identify the value of the two unknown parameters $x$ and $y$ for evaluating $f(\alpha)$ and $g(\alpha)$ (see table S1). A similar procedure has been adopted, as to evaluate $\alpha_{M}$ that comes at maximum $\mathrm{d} \alpha / \mathrm{dt}$. For the calculation of the parameters $x$ and $y$, equation 17 has been used.

$p=\frac{\alpha_{M}}{1-\alpha_{M}}(\operatorname{Eq} 17)$ 
where $p=x / y$, in which $x$ and $y$ are evaluated for each individual case.

\subsection{Statistical methods for model discrimination}

\subsubsection{Statistical analysis of models}

The comparison among the 19 different kinetics models listed in Table S1, beyond a graphical observation, is made using statistical tools. The statistics takes in input two sets of data. The reference set is composed by the experimental data of $\alpha$ or $\mathrm{d} \alpha / \mathrm{dt}$. This one will be compared with the sets composed by the data obtained with the different models. Two statistical methods are employed in parallel to verify the agreement about the best fitting kinetic model: the Residual Sum of Squares (RSS) and the Akaike Information Criterion (AICc) $\left[{ }^{40}\right]$. Later, if the best-fitting models are characterized by a different complexity (i.e. different number of parameters) an F-test

$\left.{ }^{[44}\right]$ allows to select the best one, comparing the models two by two. Detailed explanation of Akaike Information Criterion is stated in supplementary data.

The model is identified for the best possible accurately using RSS. The two parameter (AEn) or three parameter models (SB) are expected to exhibit better fits for the kinetic data in terms of smaller RSS.

RSS and AICc values are tabulated for all three $\mathrm{CO}_{2}$ concentrations for the temperature range $\left(700-1000^{\circ} \mathrm{C}\right)$ as given in table S2, S3 and S4 in the supplementary data. For each category of models considered in the study one model was selected which showed the lowest RSS and AICc values for both ( $\alpha$ vs. t) and (d $\alpha /$ dt vs. $\alpha)$. F1.5 model were having the lowest RSS and AICc value in reaction order mechanisms with the reaction order value of $n=0.91$ (listed in table $S 1$ ). In geometrical contraction models R2 model has lower RSS and AICc values with $\mathrm{n}=1.11$. In Diffusion based reaction mechanism D1 with $\mathrm{n}=0.62$ had lowest AICc. Two nucleation models (AE2 and AEn) were selected because showed similar values of RSS and AICc. This is due to 
the fact that the values of avrami exponent (n) for AEn - calculated with equation 16 - were close to somewhere around 1.9, which is almost the same value of the exponent of AE2. Similar values of $\mathrm{n}$ were also predicted from Hancock and Sharp method applied to AEn (described in supplementary data). Thus, the AEn and AE2 are of same category: the category of nucleation and grain growth.

The results for the selected models are listed in Table 2 and are plotted in Figure 8 for $20 \%$ and $40 \% \mathrm{CO}_{2}$ concentration. Similar behavior for the $30 \% \mathrm{CO}_{2}$ concentration is obtained, as can be seen in supplementary data (Figure S5 and S6).

Table 2. RSS and AICc Values for the $20 \% \mathrm{CO}_{2}$ concentration (lowest in each kinetic model category)

\begin{tabular}{lllllllllll}
\hline & & $\mathbf{7 0 0}^{\circ} \mathbf{C}$ & & $\mathbf{8 0 0}^{\circ} \mathbf{C}$ & \multicolumn{2}{c}{$\mathbf{9 0 0}^{\circ} \mathbf{C}$} & \multicolumn{2}{c}{$\mathbf{1 0 0 0}^{\circ} \mathbf{C}$} \\
method & model & RSS & AICc & \multicolumn{1}{l}{ RSS } & \multicolumn{1}{l}{ AICc } & \multicolumn{1}{l}{ RSS } & \multicolumn{1}{l}{ AICc } & \multicolumn{1}{l}{ RSS } & \multicolumn{1}{l}{ AICc } \\
\hline $\mathrm{d} \alpha / \mathrm{dt}-\alpha$ & F1.5 & 0.136506 & -4796.81 & 0.114664 & -5586.85 & 0.099529 & -6189.02 & 0.096052 & -6253.45 \\
& R2 & 0.020423 & -5889.13 & 0.019425 & -6735.57 & 0.016411 & -7448.94 & 0.015734 & -7525.22 \\
& D3 & 0.052743 & -5343.6 & 0.045676 & -6182.37 & 0.041149 & -6806.41 & 0.03937 & -6880.45 \\
& AE2 & 0.000588 & -7928.65 & 0.000535 & -9060.22 & 0.000394 & -10055.2 & 0.000586 & -9838.38 \\
& AEn & 0.000264 & -8387.92 & 0.000221 & -9628.32 & 0.000155 & -10707.2 & 0.000274 & -10371 \\
& SB & 0.000271 & -8369.78 & 0.000209 & -9665.28 & $8.94 \mathrm{E}-05$ & -11088.6 & 0.000143 & -10826.9 \\
& PT & 0.033293 & -5608.14 & 0.026461 & -6535.56 & 0.024524 & -7168.17 & 0.026009 & -7171.88 \\
\hline$\alpha-\mathrm{t}$ & F1.5 & 13.77583 & -2143.59 & 14.89744 & -2437.94 & 16.02001 & -2637.29 & 16.04467 & -2655.33 \\
& R2 & 2.669721 & -3087.13 & 5.017568 & -3142.03 & 4.96974 & -3455.45 & 5.038927 & -3469.53 \\
& D1 & 14.30321 & -2121.98 & 15.7158 & -2403.34 & 15.9027 & -2642.43 & 16.0377 & -2655.63 \\
& AE2 & 0.086214 & -5061.04 & 0.18854 & -5265.09 & 0.284452 & -5454.98 & 0.346139 & -5352.24 \\
& AEn & 0.290962 & -4359.64 & 0.01741 & -6804.41 & 0.071244 & -6420.72 & 0.354522 & -5333.42 \\
& SB & 0.257819 & -4427.17 & 0.019789 & -6719.56 & 0.05686 & -6576.35 & 0.244802 & -5591.75 \\
\hline
\end{tabular}

Figure 8-i(a) shows that AEn and SB are the closest to $\alpha_{\exp }$ at $700^{\circ} \mathrm{C}$ with $\mathrm{RSS}$ of 0.29 and 0.25 , and AICc values of -4359.6 and -4427.1 respectively. The graphical visualization shows that R2, AE2, AEn and SB are fitting well with the experimental conversion $(\alpha)$ values for $(\alpha$ vs. $t)$. For higher temperatures (Figure 8-i(b),(c),(d)), a good fitting of $\alpha_{\text {exp }}$ is limited to AEn, AE2 and SB. 
Figure 8 -ii represents $\mathrm{d} \alpha / \mathrm{dt}$ vs. $\alpha$ and it shows the R2 model fits well for temperature above $800^{\circ} \mathrm{C}$ only in the region $(0.3<\alpha<1.0)$. Models AE2, AEn and SB were instead in close agreement with $d \alpha / d_{\text {exp }}$ values in all the conditions investigated. Thus, for (d $\alpha / d t$ vs. $\left.\alpha\right)$ method only AEn, AE2 and SB models fit well with $0<\alpha<1.0$.

In conclusion, nucleation model (Avrami Erofe'ev) and SB model were in close agreement with the $\alpha_{\exp }$ and $d \alpha / d t_{\exp }$ in all the conditions investigated. These models are of same reaction mechanism except that AEn is based on two parameters and SB is an even more complex model based on three parameters. In order to identify the best suited model that describes the mechanism we adopted the F-test method to distinguish between the three models selected (AE2, AEn and SB). 


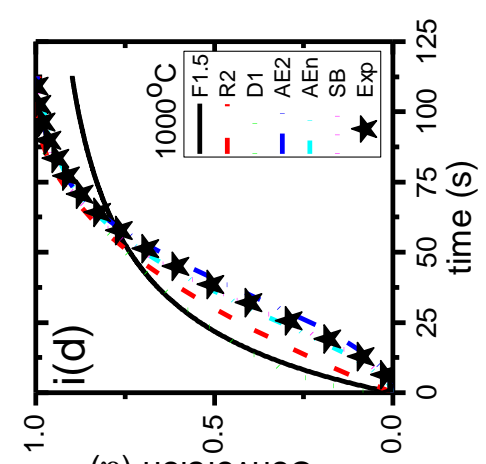

(x) ио!รıәлиоว

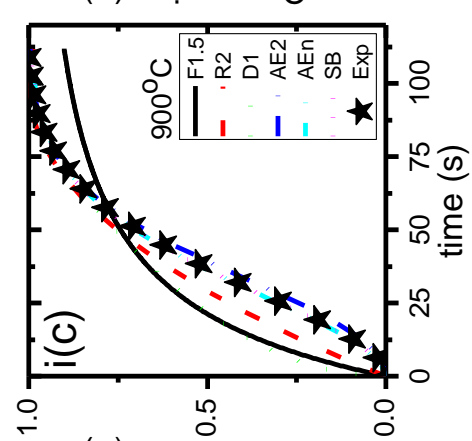

(р) ио!ฺ่әлиоว

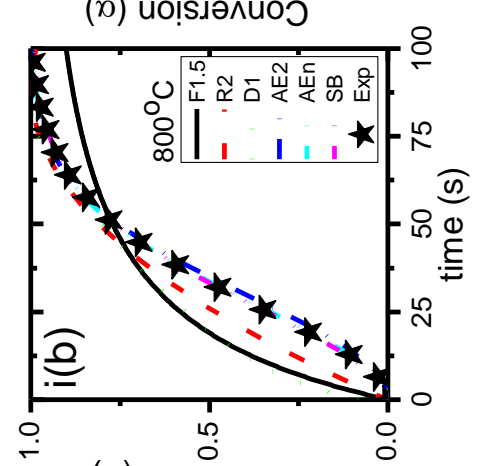

(р) ио!รıәлиоว

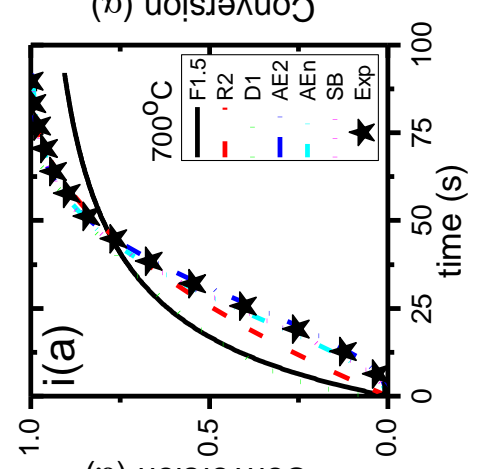

(р) ио!sıәлиоว
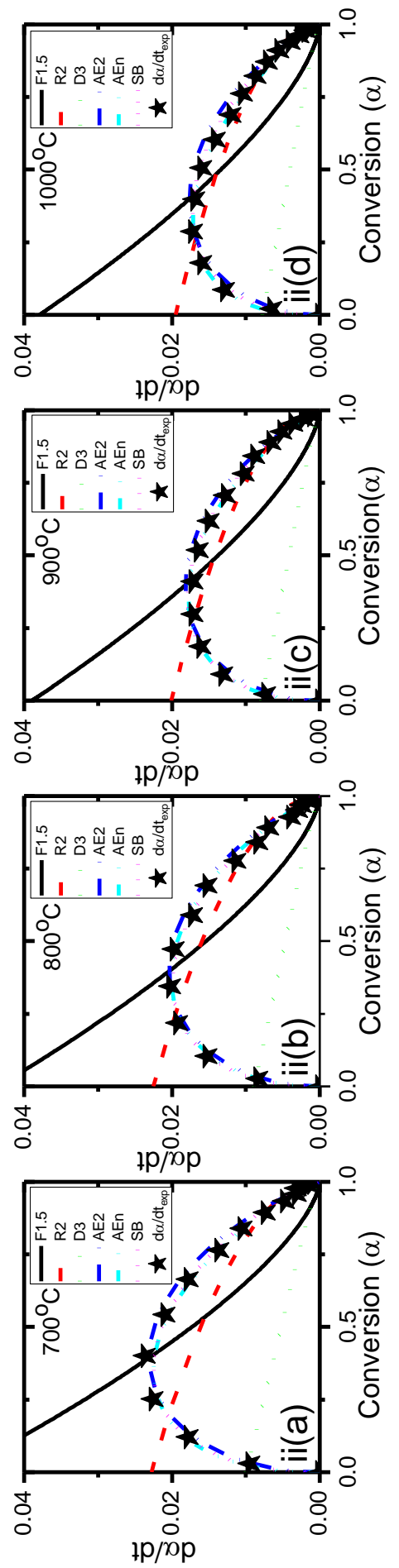

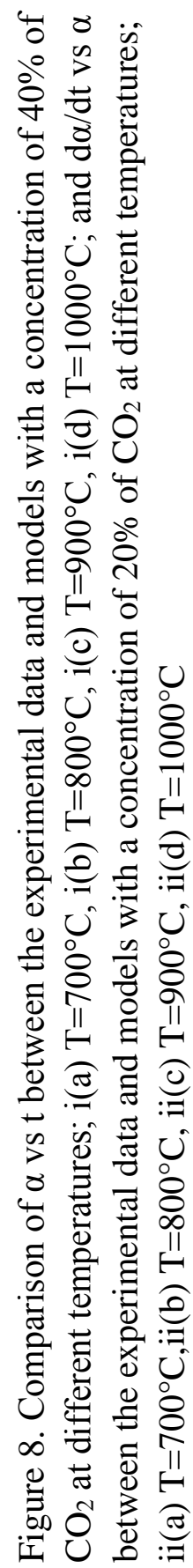

\subsection{2 r-test}

The F-test is more common method adopted to determine the statistically

significant model between versions of varying complexity. The procedure is to select the model with the smallest RSS among all the models with the same number of fitting parameters, and 
then compare the relative value of the F-ratio and the $95 \%$ upper-quantile of Fisher distribution calculated for two models with different number of fitting parameters. If the F-ratio of the two models exceeds the upper-quantile $\mathrm{F}_{0.05}\left(\mathrm{dF}_{1}-\mathrm{dF}_{2}, \mathrm{dF}_{1}\right)$, the more complicated model (with more number of parameters) is accepted as significant one. It can happen that sometimes F-test and AICc differ in agreement in their choice of the winner model $\left[{ }^{45}\right]$. The variable to calculate is called F-ratio according to the equation 18.

$F_{j}=\frac{R S S_{j}^{2}}{R S S_{\text {min }}^{2}}(\mathrm{Eq} 18)$

where $\mathrm{RSS}_{\mathrm{j}}$ is the Residual Sum of Squares of model $\mathrm{j}$ and $\mathrm{RSS}_{\min }$ is the minimum RSS between the two models. F-ratio follows the Fisher distribution with $\mathrm{m}$ and $\mathrm{n}$ degrees of freedom (which correspond to the sizes of the samples).

Fixing $\alpha$, which is the level of risk (it is usual to refer to $1-\alpha$ as level of confidence), the acceptance limits, called quantiles of order 1- $\alpha / 2$, can be extrapolated from the table of the Fisher distribution cumulative probability function.

After the identification of models which were with lowest RSS and AICc values, three models AE2, AEn and SB model were in agreement with experimental conversion values and $F$ test has been applied for both the methods adopted ( $\alpha$ vs. $t$ and $d \alpha /$ dt vs. $\alpha$ ).

The F-test results for $20 \% \mathrm{CO}_{2}$ concentration is listed in Table 3. F-test results for $30 \%$ and $40 \%$ $\mathrm{CO}_{2}$ concentration (Table S5 and Table S6) can be seen in supplementary data.

It is yielded that for temperature $700^{\circ} \mathrm{C}, \mathrm{SB}$ model was the winner for $\mathrm{d} \alpha / \mathrm{dt}$ vs. $\mathrm{t}$ method and AEn for $\alpha$ vs. t. Considering $\mathrm{d} \alpha / \mathrm{dt}$ vs $\alpha$ method for all concentration of $\mathrm{CO}_{2}$ in the inlet, SB model is the winner model for temperatures $700^{\circ} \mathrm{C}, 800^{\circ} \mathrm{C}$ and $1000^{\circ} \mathrm{C}$ except at $900^{\circ} \mathrm{C}$ where 
AEn model is the winner. For $\alpha$ vs $\mathrm{t}$ method, AEn model is the winner except at $800^{\circ} \mathrm{C}$ with $20 \%$ $\mathrm{CO}_{2}$ and $1000^{\circ} \mathrm{C}$ with $30 \% \mathrm{CO}_{2}$, where $\mathrm{SB}$ is the winner model.

Globally, the SB model is the winner in 32 of the F-tests, while AEn in 27 and AE2 only in 13. Therefore, with the methodology adopted both AE and SB model were in agreement with experimental data, but AE2 and AEn passes the F-test in fewer conditions than SB, which revealed to be the winner model for the larger number of conditions in either of the methods adopted.

Table 3. F-test for the $20 \%$ CO2 concentration.

\begin{tabular}{|c|c|c|c|c|c|}
\hline Temperature & Method & $\begin{array}{l}\text { Cases } \\
\text { compared }\end{array}$ & F-ratio & $\begin{array}{l}\text { Upper } \\
\text { quantile }\end{array}$ & $\begin{array}{l}\text { Winner } \\
\text { model }\end{array}$ \\
\hline \multirow[t]{6}{*}{700} & $\mathrm{~d} \alpha / \mathrm{dt}-\mathrm{t}$ & AEn/AE2 & 1.0113 & 1.1436 & AE2 \\
\hline & & SB/AE2 & 0.9627 & 0.8744 & SB \\
\hline & & SB/AEn & 0.9519 & 0.8744 & SB \\
\hline & $\alpha-\mathrm{t}$ & AEn/AE2 & 1.0170 & 1.1432 & AE2 \\
\hline & & SB/AE2 & 0.9224 & 0.8716 & SB \\
\hline & & SB/AEn & 1.0198 & 1.1473 & AEn \\
\hline \multirow[t]{6}{*}{800} & $\mathrm{~d} \alpha / \mathrm{dt}-\mathrm{t}$ & AEn/AE2 & 1.0308 & 1.1341 & AE2 \\
\hline & & SB/AE2 & 0.9595 & 0.8740 & SB \\
\hline & & SB/AEn & 0.9338 & 0.8740 & SB \\
\hline & $\alpha-t$ & AEn/AE2 & 1.0494 & 1.1334 & AE2 \\
\hline & & $\mathrm{SB} / \mathrm{AE} 2$ & 0.9215 & 0.8785 & SB \\
\hline & & SB/AEn & 0.9674 & 0.8785 & SB \\
\hline \multirow[t]{6}{*}{900} & $\mathrm{~d} \alpha / \mathrm{dt}-\mathrm{t}$ & AEn/AE2 & 1.0060 & 1.1274 & AE2 \\
\hline & & $\mathrm{SB} / \mathrm{AE} 2$ & 1.0699 & 1.1274 & AE2 \\
\hline & & SB/AEn & 1.0635 & 1.1274 & AEn \\
\hline & $\alpha-\mathrm{t}$ & AEn/AE2 & 1.0098 & 1.1266 & AE2 \\
\hline & & $\mathrm{SB} / \mathrm{AE} 2$ & 0.9236 & 0.8828 & SB \\
\hline & & SB/AEn & 1.0107 & 1.1326 & AEn \\
\hline \multirow[t]{6}{*}{1000} & $\mathrm{~d} \alpha / \mathrm{dt}-\mathrm{t}$ & AEn/AE2 & 0.9817 & 0.8893 & AEn \\
\hline & & SB/AE2 & 0.9644 & 0.8893 & SB \\
\hline & & SB/AEn & 0.9824 & 0.8893 & SB \\
\hline & $\alpha-\mathrm{t}$ & Aen/AE2 & 0.9628 & 0.8894 & AEn \\
\hline & & SB/AE2 & 0.9263 & 0.8831 & SB \\
\hline & & SB/AEn & 1.0636 & 1.1322 & AEn \\
\hline
\end{tabular}

\subsection{Kinetic parameter evaluation:}


After the selection of SB as the best-fitting model, the kinetic parameters estimation is done. The $\ln (\mathrm{K})$ has been plotted versus inverse of temperature $(1 / \mathrm{T})$ for each concentration of $\mathrm{CO}_{2}$ as described through equation 14. Figure 9(a) represents the $\ln (\mathrm{K})$ vs $(1 / \mathrm{T})$ plot for the three concentrations. The negative slope yields the activation energy for each concentration. The average activation energy evaluated from the three concentrations is $78.5 \mathrm{~kJ} / \mathrm{mol}$. The intercept of the value would be $\ln \left(\mathrm{AP}^{\mathrm{m}}\right)$, as described by equation 15, which is plotted in Figure 9(b) against natural logarithm of partial pressure of $\mathrm{CO}_{2}$.
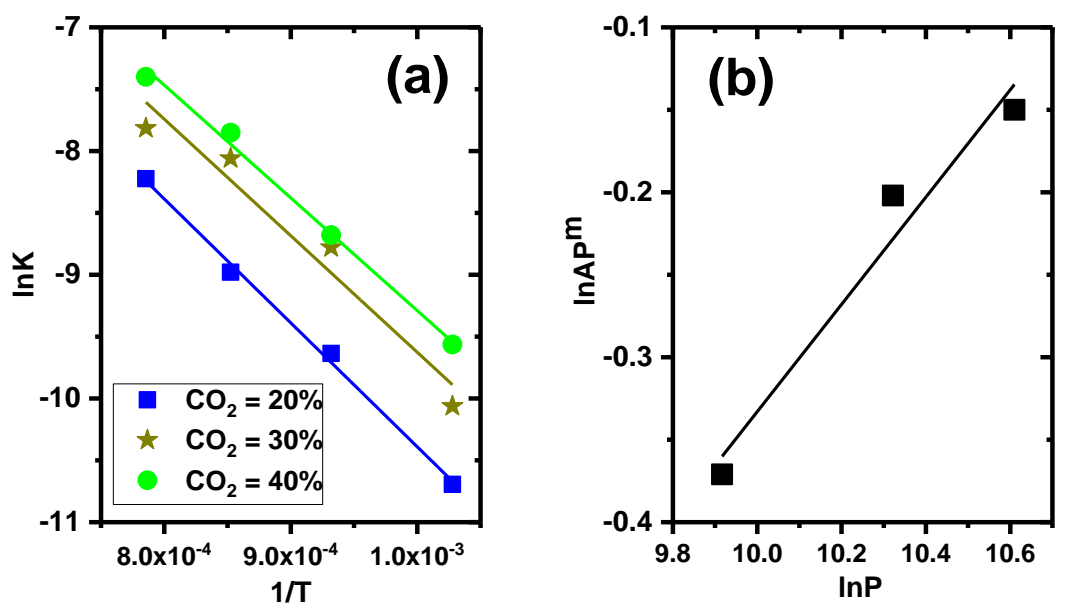

Figure 9. (a) $\ln (\mathrm{K})$ vs $(1 / \mathrm{T})$ Arrhenius plot of the oxidation reaction for SB model, (b) $\ln \left(\mathrm{AP}^{\mathrm{m}}\right)$ vs $\ln (\mathrm{P})$ plot for oxidation reaction order determination.

From Figure 9(b) the reaction order obtained is 0.3253 and the pre-exponential factor is $0.028 \mathrm{~s}^{-1} \mathrm{~Pa}^{\mathrm{m}}$. The value of activation energy is validated using an analytical model developed by Bulfin et al $\left[{ }^{26}\right]$, in which activation energy is obtained by plotting between $\ln (\delta /(x-\delta))$ vs $1 / \mathrm{T}$. Here $x$ is the maximum non-stoichiometry that an oxygen carrier can reach during oxidation and reduction step. For ceria the value of $x$ reported as $0.35\left[{ }^{26}\right]$. Figure S7 (supplementary data) represents the analytical method adopted to verify the activation energy, and it came out as $\sim 80$ 
$\mathrm{kJ} / \mathrm{mol}$ which is in-line with the kinetic methodology we adopted in our study and found it to be $\sim 78.5 \mathrm{~kJ} / \mathrm{mol}$.

\section{Conclusion}

This work presents a detailed kinetics study of $\mathrm{CO}_{2}$ splitting using ceria. The time resolved kinetics were measured in a horizontal tubular reactor at atmospheric pressure. The ceria sample was alternatively exposed to $5 \% \mathrm{H}_{2}$ in Argon mixture in the reduction step to remove the lattice oxygen, and $\mathrm{CO}_{2}$ in the oxidations step to produce $\mathrm{CO}$ in the redox cycle. Tests were performed under isothermal conditions $\left(700-1000^{\circ} \mathrm{C}\right)$ for multiple redox cycles for three $\mathrm{CO}_{2}$ concentrations between $20 \%-40 \%$ in Argon. Experiments showed that with increase of temperature the total $\mathrm{CO}$ production increases. For instance the total $\mathrm{CO}$ production at $700^{\circ} \mathrm{C}$ was $9.19 \mathrm{ml} / \mathrm{g}$ and peak production was $13.25 \mathrm{ml} / \mathrm{min} / \mathrm{g}$, and for $1000^{\circ} \mathrm{C}$ the total $\mathrm{CO}$ production was $28.15 \mathrm{ml} / \mathrm{g}$ and peak rate was $29.7 \mathrm{ml} / \mathrm{min} / \mathrm{g}$ for $\mathrm{CO}_{2}$ concentration of $20 \%$. For higher concentration of $\mathrm{CO}_{2}(40 \%)$ the total $\mathrm{CO}$ production increased to $33.66 \mathrm{ml} / \mathrm{g}$ and the peak rate to $46 \mathrm{ml} / \mathrm{min} / \mathrm{g}$ for $1000^{\circ} \mathrm{C}$. The total $\mathrm{CO}$ production linearly increased with the increase of temperature, and the effect of $\mathrm{CO}_{2}$ concentration on total production was minimal. However, the effect of concentration of $\mathrm{CO}_{2}$ was seen with respect to peak rate signifying the time for conversion reduction.

In order to identify the reaction mechanism and kinetic model, statistical approach was adopted to select among different reactions models by fitting them to experimental reaction rates. The activation energies, the pre-exponential factors, and the reaction orders were determined. By determining the RSS and AICc values kinetic models were selected, and based on the complexity and the number of parameters the F-test considering upper quantile was used to select the best

model. The results showed that the AEn and SB model are both suitable for describing the 
oxidation reaction, but SB model was the best-fitting one for most of the conditions of temperature and reactant concentration. The activation energy obtained considering the SB model was determined to be $\sim 78.5 \mathrm{~kJ} / \mathrm{mol}$, in agreement with the literature. The present study gives a clear understanding in the model selection and mechanism of reaction for the entire range of conversion rate $(0<\alpha<1.0)$, which would help in designing the chemical looping $\mathrm{CO}_{2}$ splitting for packed bed or fluidized bed reactors for large scale system.

Acknowledgments: The research presented is performed within the framework of the Erasmus Mundus Joint Doctorate SELECT+ program 'Environomical Pathways for Sustainable Energy Systems' and funded with support from the Education, Audiovisual, and Culture Executive Agency (EACEA) of the European Commission. This publication reflects the views only of the author(s), and the Commission cannot be held responsible for any use, which may be made of the information contained therein. J. Llorca is a Serra Húnter Fellow and is grateful to ICREA Academia program and MINECO/FEDER project ENE2015-63969-R.

\section{Nomenclature:}

\begin{tabular}{ll}
\hline Property & Value \\
\hline$X_{C O, \text { out }}$ & mole fraction of CO at the exit of the reactor \\
$\dot{n}_{o x, \text { out }}$ & total molar outflow rate of the gas mixture \\
$P^{0}$ & Pressure at standard temperature and pressure (STP) \\
$T^{0}$ & temperature at standard temperature and pressure $(\mathrm{STP})$ \\
$\dot{V}_{o x, \text { in }}^{0}$ & total volumetric inflow rate at standard temperature and \\
$m_{\mathrm{CeO} O_{2}}$ & pressure (STP) \\
$\delta_{1}$ & Mass of the ceria sample used. \\
$\delta_{2}$ & non-stoichiometry reached after reduction step \\
$\delta$ & non-stoichiometry reached after the oxidation of ceria \\
$\mathrm{n}_{\mathrm{O}}$ & step \\
$\dot{\omega}_{\mathrm{CO}}$ & bulk-phase non-stoichiometry change
\end{tabular}




\begin{tabular}{ll}
$\mathrm{M}_{\mathrm{CeO}_{2}}$ & molecular weight of ceria \\
$\mathrm{n}_{\mathrm{CeO}_{2}}$ & moles of ceria \\
$\alpha$ & conversion \\
$E_{a}$ & activation energy \\
$R$ & gas constant that is equal to $8.314 \mathrm{~J}-\mathrm{mol} / \mathrm{K}$. \\
$T$ & Temperature of the reaction $(\mathrm{K})$ \\
$A$ & Arrhenius exponent \\
$K$ & Reaction rate constant \\
$g(\alpha)$ & Integral function of $f(\alpha)$ \\
$\alpha_{\mathrm{M}}$ & Conversion value at the maximum $(\mathrm{d} \alpha / \mathrm{dt})$ \\
$\mathrm{n}$ & Avrami exponent \\
$D$ & Grain size \\
$\lambda$ & X-ray wavelength \\
$\beta$ & line broadening at half the maximum intensity \\
$\theta$ & Braggs angle \\
$\mathrm{F}$ & F ratio \\
$\mathrm{RSS}$ & Residual sum of squares \\
$\mathrm{AIC}$ & Akaike information criterion \\
$\mathrm{x}, \mathrm{y}$ & Sestak-Berggren $(\mathrm{SB})$ model parameters \\
& \\
\hline
\end{tabular}

\section{References:}

1. Leung, D. Y. C., Caramanna, G. \& Maroto-Valer, M. M. An overview of current status of carbon dioxide capture and storage technologies. Renew. Sustain. Energy Rev. 39, 426443 (2014).

2. Daza, Y. A., Kent, R. A., Yung, M. M. \& Kuhn, J. N. Carbon dioxide conversion by reverse water-gas shift chemical looping on perovskite-type oxides. Ind. Eng. Chem. Res. 53, 5828-5837 (2014).

3. Kim, J. et al. Methanol production from CO2 using solar-thermal energy: process development and techno-economic analysis. Energy Environ. Sci. 4, 3122 (2011).

4. Abanades, S. \& Villafan-Vidales, H. I. CO2 and H2O conversion to solar fuels via twostep solar thermochemical looping using iron oxide redox pair. Chem. Eng. J. 175, 368375 (2011). 
5. Abanades, S. \& Flamant, G. Thermochemical hydrogen production from a two-step solardriven water-splitting cycle based on cerium oxides. Sol. Energy 80, 1611-1623 (2006).

6. Furler, P., Scheffe, J. R. \& Steinfeld, A. Syngas production by simultaneous splitting of $\mathrm{H} 2 \mathrm{O}$ and $\mathrm{CO} 2$ via ceria redox reactions in a high-temperature solar reactor. Energy Environ. Sci. 5, 6098-6103 (2012).

7. Chueh, W. C. et al. High-Flux Solar-Driven Thermochemical Dissociation of $\mathrm{CO} 2$ and H2O Using Nonstoichiometric Ceria. Science 330, 1797-1801 (2010).

8. Furler, P. et al. Solar Thermochemical CO 2 Splitting Utilizing a Reticulated Porous Ceria Redox System. Energy \& Fuels 26, 7051-7059 (2012).

9. Stamatiou, A., Loutzenhiser, P. G. \& Steinfeld, A. Solar Syngas Production via H 2 O/CO 2 -Splitting Thermochemical Cycles with $\mathrm{Zn} / \mathrm{ZnO}$ and $\mathrm{FeO} / \mathrm{Fe} 3 \mathrm{O} 4$ Redox Reactions $\uparrow$. Chem. Mater. 22, 851-859 (2010).

10. Le Gal, A., Abanades, S. \& Flamant, G. CO 2 and H 2 O Splitting for Thermochemical Production of Solar Fuels Using Nonstoichiometric Ceria and Ceria/Zirconia Solid Solutions. Energy \& Fuels 25, 4836-4845 (2011).

11. Abanades, S. \& Le Gal, A. CO2 splitting by thermo-chemical looping based on ZrxCe1-xO2 oxygen carriers for synthetic fuel generation. Fuel 102, 180-186 (2012).

12. Rudisill, S. G. et al. Enhanced Oxidation Kinetics in Thermochemical Cycling of $\mathrm{CeO} 2$ through Templated Porosity. J. Phys. Chem. C 117, 1692-1700 (2013).

13. Furler, P. et al. Thermochemical CO 2 splitting via redox cycling of ceria reticulated foam structures with dual-scale porosities. Phys. Chem. Chem. Phys. 16, 10503-10511 (2014).

14. Venstrom, L. J., De Smith, R. M., Hao, Y., Haile, S. M. \& Davidson, J. H. Efficient Splitting of CO 2 in an Isothermal Redox Cycle Based on Ceria. Energy \& Fuels 28, 2732-2742 (2014).

15. Zhao, B., Huang, C., Ran, R., Wu, X. \& Weng, D. Two-step thermochemical looping using modified ceria-based materials for splitting CO2. J. Mater. Sci. 51, 2299-2306 (2016). 
16. Ackermann, S. et al. Kinetics of CO 2 Reduction over Nonstoichiometric Ceria. J. Phys. Chem. C 119, 16452-16461 (2015).

17. Zhao, Z., Uddi, M., Tsvetkov, N., Yildiz, B. \& Ghoniem, A. F. Enhanced intermediatetemperature CO 2 splitting using nonstoichiometric ceria and ceria-zirconia. Phys. Chem. Chem. Phys. 19, 25774-25785 (2017).

18. Venstrom, L. J., Petkovich, N., Rudisill, S., Stein, A. \& Davidson, J. H. The Effects of Morphology on the Oxidation of Ceria by Water and Carbon Dioxide. J. Sol. Energy Eng. 134, 11005 (2012).

19. Zhu, L. \& Lu, Y. Reactivity and efficiency of ceria-based oxides for solar CO2 splitting via isothermal and near-isothermal cycles. Energy \& Fuels acs.energyfuels.7b03284 (2017). doi:10.1021/acs.energyfuels.7b03284

20. Knoblauch, N. et al. Surface controlled reduction kinetics of nominally undoped polycrystalline $\mathrm{CeO}_{2}$. Phys. Chem. Chem. Phys. 17, 5849-5860 (2015).

21. Zhao, Z., Uddi, M., Tsvetkov, N., Yildiz, B. \& Ghoniem, A. F. Redox Kinetics Study of Fuel Reduced Ceria for Chemical-Looping Water Splitting. J. Phys. Chem. C 120, 1627116289 (2016).

22. Ramos-Fernandez, E. V., Shiju, N. R. \& Rothenberg, G. Understanding the solar-driven reduction of $\mathrm{CO}_{2}$ on doped ceria. $R S C A d v .4$, 16456-16463 (2014).

23. Knoblauch, N. et al. Ceria: Recent Results on Dopant-Induced Surface Phenomena. Inorganics 5, 76 (2017).

24. Tou, M., Michalsky, R. \& Steinfeld, A. Solar-Driven Thermochemical Splitting of CO2and In Situ Separation of CO and O2across a Ceria Redox Membrane Reactor. Joule 1, 146-154 (2017).

25. Zhao, Z., Uddi, M., Tsvetkov, N., Yildiz, B. \& Ghoniem, A. F. Redox Kinetics and Nonstoichiometry of Hydrogen Production.

26. Bulfin, B. et al. Analytical Model of $\mathrm{CeO} 2$ Oxidation and Reduction. J. Phys. Chem. C 117, 24129-24137 (2013). 
27. Arifin, D. Study of redox reactions to split water and carbon dioxide. (University of Colorado, 2013).

28. Ackermann, S., Scheffe, J. R. \& Steinfeld, A. Diffusion of oxygen in ceria at elevated temperatures and its application to $\mathrm{H} 2 \mathrm{O} / \mathrm{CO} 2$ splitting thermochemical redox cycles. $J$. Phys. Chem. C 118, 5216-5225 (2014).

29. Muhich, C. \& Steinfeld, A. Principles of doping ceria for the solar thermochemical redox splitting of $\mathrm{H}_{2} \mathrm{O}$ and $\mathrm{CO}_{2}$. J. Mater. Chem. A 5, 15578-15590 (2017).

30. Hoes, M., Muhich, C. L., Jacot, R., Patzke, G. R. \& Steinfeld, A. Thermodynamics of paired charge-compensating doped ceria with superior redox performance for solar thermochemical splitting of $\mathrm{H}_{2} \mathrm{O}$ and $\mathrm{CO}_{2}$. J. Mater. Chem. A (2017). doi:10.1039/C7TA05824A

31. Avrami, M. Kinetics of Phase Change. I General Theory. J. Chem. Phys. 7, 1103-1112 (1939).

32. Avrami, M. Kinetics of Phase Change. II Transformation-Time Relations for Random Distribution of Nuclei. J. Chem. Phys. 8, 212-224 (1940).

33. Avrami, M. Granulation, Phase Change, and Microstructure Kinetics of Phase Change. III. J. Chem. Phys. 9, 177-184 (1941).

34. Erofe'ev BN. Generalized chemical kinetics equation and its application to reaction with solid participants. Dokl. Akad. Nauk SSSR 52, 515 (1946).

35. Bhatia, S. K. \& Perlmutter, D. D. A random pore model for fluid-solid reactions: I. Isothermal, kinetic control. AIChE J. 26, 379-386 (1980).

36. Šesták, J. \& Berggren, G. Study of the kinetics of the mechanism of solid-state reactions at increasing temperatures. Thermochim. Acta 3, 1-12 (1971).

37. Prout, EG; Tompkins, F. The thermal decomposition of potassium permanganate. Trans. Faraday Soc. 40, 488-98 (1944).

38. Zafar, Q., Mattisson, T. \& Gevert, B. Redox Investigation of Some Oxides of TransitionState Metals $\mathrm{Ni}, \mathrm{Cu}, \mathrm{Fe}$, and $\mathrm{Mn}$ Supported on $\mathrm{SiO} 2$ and MgAl 2 O 4. Energy \& Fuels 20, 
34-44 (2006).

39. Galwey AK; Brown ME. Kinetic background to thermal analysis and calorimetry. in Handbook of thermal analysis and calorimetry Vol. 1 Principles and practice 147-216 (1998).

40. Burnham, Kenneth P., Anderson, D. R. Model selection and multi-model inference: a practical information-theoretic approach. (Springer-Verlag, 2002).

41. Janković, B., Adnađević, B. \& Mentus, S. The kinetic study of temperature-programmed reduction of nickel oxide in hydrogen atmosphere. Chem. Eng. Sci. 63, 567-575 (2008).

42. Han, L., Zhou, Z. \& Bollas, G. M. Heterogeneous modeling of chemical-looping combustion. Part 1: Reactor model. Chem. Eng. Sci. 104, 233-249 (2013).

43. HANCOCK, J. D. \& SHARP, J. H. Method of Comparing Solid-State Kinetic Data and Its Application to the Decomposition of Kaolinite, Brucite, and BaCO3. J. Am. Ceram. Soc. 55, 74-77 (1972).

44. AM, M. Introduction of the theory of statistics. (McGraw-Hill, 1974).

45. Ludden, T. M., Beal, S. L. \& Sheiner, L. B. Comparison of the Akaike Information Criterion, the Schwarz criterion and the $\mathrm{F}$ test as guides to model selection. $J$. Pharmacokinet. Biopharm. 22, 431-445 (1994). 